\section{Exercise answers}

Page 3. Figure 7.

\begin{tabular}{|lllllll|}
\hline$A$ & 1 & 0 & 0 & 1 & $=$ \\
\hline$B$ & & 1 & 1 & 1 & 0 & $=14$ \\
\hline$C$ & & 0 & 1 & 1 & 1 & $=7$ \\
\hline$D$ & & 0 & 1 & 0 & 1 & $=5$ \\
\hline$E$ & 1 & 0 & 1 & 1 & 1 & $=23$ \\
\hline F & 1 & 1 & 0 & 0 & 0 & $=24$ \\
\hline G & 1 & 1 & 0 & 1 & 0 & $=26$ \\
\hline H & 1 & 0 & 1 & 0 & 1 & $=21$ \\
\hline
\end{tabular}

Page 6.

$76,137,27,100,119,64,93$.

\begin{tabular}{|cccccccc|c|}
\hline 128 & 64 & 32 & $\mathbf{1 6}$ & $\mathbf{8}$ & $\mathbf{4}$ & $\mathbf{2}$ & $\mathbf{1}$ & No. \\
\hline & 1 & 0 & 0 & 1 & 1 & 0 & 0 & 76 \\
\hline 1 & 0 & 0 & 0 & 1 & 0 & 0 & 1 & 137 \\
\hline & & & 1 & 1 & 0 & 1 & 1 & 27 \\
\hline 1 & 1 & 0 & 0 & 1 & 0 & 0 & 100 \\
\hline 1 & 1 & 1 & 0 & 1 & 1 & 1 & 119 \\
\hline 1 & 0 & 0 & 0 & 0 & 0 & 0 & 64 \\
\hline 1 & 0 & 1 & 1 & 1 & 0 & 1 & 93 \\
\hline
\end{tabular}

Page 7. The base of the quad numbering system is 4 .
Page 7. Figure 1.10.

\begin{tabular}{|c|c|c|c|}
\hline \multicolumn{4}{|c|}{ Name and base. } \\
Binary (2) & Quad(4) & Octal (8) & Decimal (10) \\
\hline 0 & 0 & 0 & 0 \\
1 & 1 & 1 & 1 \\
01 & 2 & 2 & 2 \\
11 & 3 & 3 & 3 \\
100 & 10 & 4 & 4 \\
101 & 11 & 5 & 5 \\
110 & 12 & 6 & 6 \\
111 & 13 & 7 & 7 \\
1000 & 20 & 10 & 8 \\
1001 & 21 & 11 & 9 \\
1010 & 22 & 12 & 10 \\
1011 & 23 & 13 & 11 \\
1100 & 30 & 14 & 12 \\
1101 & 31 & 15 & 13 \\
1110 & 32 & 16 & 14 \\
1111 & 33 & 17 & 15 \\
\hline
\end{tabular}

Page 8. A four bit word can represent up to 16 decimal numbers $(0-15)$.

Page 8. The maximum decimal number represented by a five bit word is 31 .

Page 9. Figure 1.15. Decimal 5.

Page 9. Figure 1.16. Decimal 14.
Page 17. Binary coded decimal number 796.

\begin{tabular}{|c|c|c|}
\hline 0111 & 1001 & 0110 \\
7 & 9 & 6 \\
\hline
\end{tabular}

Page 18. $R=\frac{V_{s}-V d}{I d} \quad \therefore \quad R=\frac{12-2}{20 \mathrm{ma}}$

$$
=\frac{10}{20 \mathrm{ma}}=\frac{10 \mathrm{~K} \Omega}{20}=500 \Omega
$$

\section{Appendix}

Convert 1019 to binary form

$$
\begin{aligned}
& 1019 \div 2=509 \quad 1 \text { (LSB) } \\
& 509 \div 2=254 \quad 1 \\
& 254 \div 2=1270 \\
& 127 \div 2=63 \quad 1 \\
& 63 \div 2=31 \quad 1 \\
& 31 \div 2=15 / 1 \\
& 15 \div 2=7 \quad 1 \\
& 7 \div 2=3 \quad 1 \\
& 3 \div 2=1
\end{aligned}
$$

Decimal $1019=$ binary 1111111011 or $1019_{10}=1111111011_{2}$ 